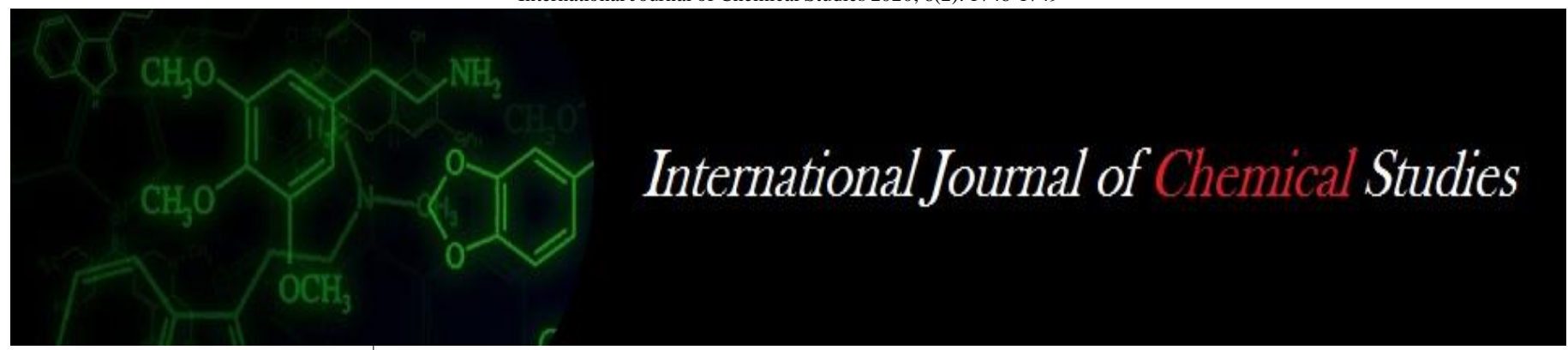

P-ISSN: 2349-8528

E-ISSN: 2321-4902

www.chemijournal.com

IJCS 2020; 8(2): 1746-1749

(C) 2020 IJCS

Received: 16-01-2020

Accepted: 18-02-2020

\section{R Gladis}

Department of Soil Science \& Agricultural Chemistry, College of Agriculture, Vellayani.

Agricultural University, Kerala, India

\section{Biju Joseph}

Department of Soil Science \& Agricultural Chemistry, College of Agriculture, Vellayani. Agricultural University, Kerala, India

\section{B Aparna}

Department of Soil Science \& Agricultural Chemistry, College of Agriculture, Vellayani. Agricultural University, Kerala, India

\section{Corresponding Author:}

\section{R Gladis}

Department of Soil Science \& Agricultural Chemistry, College of Agriculture, Vellayani.

Agricultural University, Kerala, India

\section{Delineation and mapping of micronutrients status in the rice soils of Kasargode district of Kerala}

\author{
R Gladis, Biju Joseph and B Aparna
}

DOI: https://doi.org/10.22271/chemi.2020.v8.i2aa.9012

\begin{abstract}
Micronutrient deficiency in soil has become widespread in recent years and has resulted in low crop yields. Information on micronutrient status of rice soils is very much relevant for identifying constraints in rice production and to develop judicious fertilization to attain sustained productivity. The midland rice fields in Kasargode district constitute the drainage basins of hills and hillocks. Soil is lateritic and acidic in nature with high accumulation of reduced forms of iron and manganese and invariably poor in micronutrients boron, copper and zinc. In the present investigation 3500 surface soil samples were collected from selected 175 paddy fields of Kasargode and assessed for extent of soil acidity and available $(0.1 \mathrm{~N} \mathrm{HCl}$ extractable $)$ micronutrient status. Soil acidity is a serious constraint in these soils, which are very strongly acidic to neutral in reaction with $\mathrm{pH}$ values ranged from 4.21to 7.44. The content of $0.1 \mathrm{~N} \mathrm{HCl}$ extractable $\mathrm{Fe}, \mathrm{Mn}, \mathrm{Zn}$ and $\mathrm{Cu}$ in soil varied from $52.21-414.9,12.21-54.80,0.66-$ $38.5,0.18-36.5 \mathrm{mg} \mathrm{kg}^{-1}$ respectively and hot water soluble boron varied from $0.027-0.948 \mathrm{mg} \mathrm{kg}^{-1}$. The available copper and zinc were found to be adequate and hot water soluble boron was deficient in these soils. The soil available iron and manganese was found to be excess and iron toxicity (> $200 \mathrm{mg} \mathrm{kg}$ $\left.{ }^{-1}\right)$ problem was also observed in some soils of the study area.
\end{abstract}

Keywords: Rice soils, micronutrients, soil acidity, iron toxicity, GIS mapping

\section{Introduction}

Land use plays a vital role in governing the nutrient dynamics and soil fertility (Venkatesh et al., 2003). Assessment of soil properties along with nutrient status particularly micronutrients of various land use system is important for identifying soil constrains and for attaining sustained productivity (Somasundaram et al., 2009). Availability of micronutrients is influenced by their distribution in soil and other physico - chemical properties of soil.

The midland rice fields in Kasaragode district constitute the drainage basins of hills and hillocks, soil being lateritic and acidic in nature with high accumulation of reduced forms of iron and manganese and invariably poor is micronutrients. The present investigation was under taken to study the extent of soil acidity and status of available micronutrients viz., $\mathrm{Fe}, \mathrm{Mn}$, $\mathrm{Zn}, \mathrm{Cu}$ and $\mathrm{B}$ in rice ecosystems of Kasaragode.

\section{Materials and methods}

The selected midland rice fields of Kasaragode situated in the northern part of Kerala lies between $12^{\circ} 06^{\prime} 41^{\prime \prime}$ and $12^{\circ} 41^{\prime} 32^{\prime \prime} \mathrm{N}$ latitude and $74^{\circ} 59^{\prime} 31^{\prime \prime}$ and $75^{\circ} 15^{\prime} 59^{\prime \prime}$ E longitude. The average elevation is 50 to $300 \mathrm{~m}$ above mean sea level. 3500 surface $(0-15 \mathrm{~cm})$ soil samples at random were collected from selected rice growing fields during 2015 and 2016 to assess the extent of soil acidity and available micronutrient status of soil.

Soil $\mathrm{pH}$ was determined in 1:2.5 (soil: water) suspension using $\mathrm{pH}$ meter. The available Fe, $\mathrm{Mn}, \mathrm{Zn}$ and $\mathrm{Cu}$ in soils were extracted with $0.1 \mathrm{~N} \mathrm{HCl}$ extract and the quantity was determined using AAS. The available B was extracted with hot water and quantified using spectrophotometer after developing colour using azomethine $-\mathrm{H}$ reagent. The data were interpreted as deficient and sufficient based on the critical level of nutrients suggested by KAU. Iron toxicity problem in the study area was also estimated based on the critical values. The maps on available boron status and iron toxicity were prepared using Arc GIS software. 

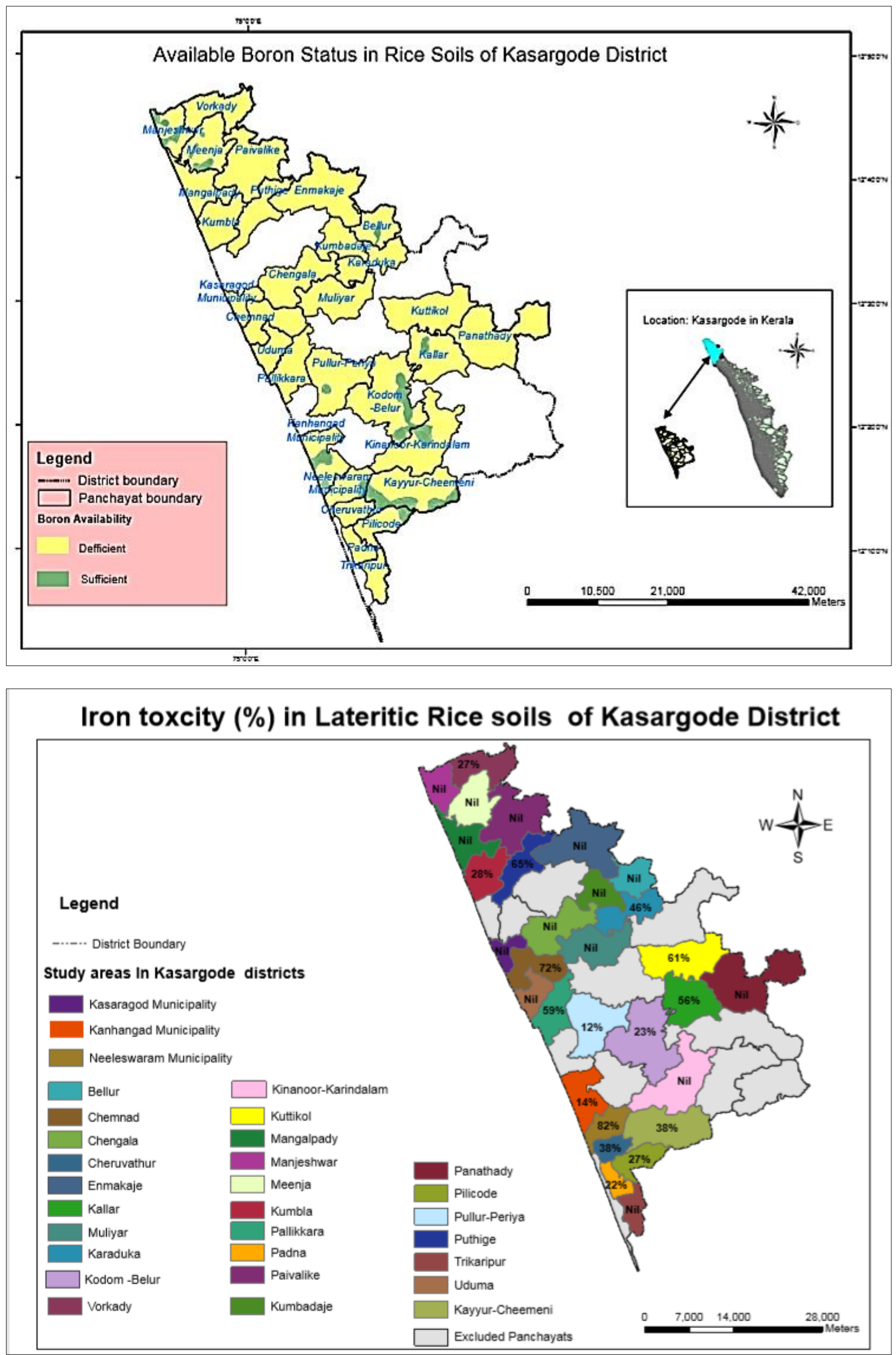


\section{Results and discussion \\ Soil acidity}

The $\mathrm{pH}$ values of rice soils are given in Table 1, which varied from 4.21 to 7.44 indicating that the soils are very strongly acidic to neutral in reaction except Padana soils where $\mathrm{pH}$ was 6.17 to 9.56 (neutral to alkaline reaction). The lowest $\mathrm{pH}$ was recorded in Pilicode and the highest in Padana. The reasons for the low $\mathrm{pH}$ is that the rice soils are lateritic and derived from acidic parent material. The dominance of $\mathrm{Fe}, \mathrm{Mn}$ and $\mathrm{Al}$ in these soils also contribute to soil acidity due to the hydrolysis of these ions in exchange sites of soil complexes. Similar results were also reported by Jena (2013) ${ }^{[2]}$. The higher $\mathrm{pH}$ in Padana soils is attributed to the high amount of alkaline earth minerals and intrusion of sea water into rice fields.

Table 1: Soil acidity in rice soils of Kasargod

\begin{tabular}{|c|c|c|c|c|c|c|c|}
\hline \multirow[t]{2}{*}{ S. No. } & \multirow[t]{2}{*}{ Location } & \multicolumn{2}{|c|}{$\mathrm{pH}$} & \multirow[t]{2}{*}{ S. No. } & \multirow[t]{2}{*}{ Location } & \multicolumn{2}{|c|}{$\mathrm{pH}$} \\
\hline & & Range & Mean & & & Range & Mean \\
\hline 1 & Pilicode & $4.21-6.14$ & 5.32 & 16 & Kumbla & $5.36-6.12$ & 5.88 \\
\hline 2 & Cheruvathur & $4.37-5.92$ & 5.43 & 17 & Enmakaje & $4.55-5.67$ & 5.23 \\
\hline 3 & Padana & $6.17-9.56$ & 7.91 & 18 & Nileswar & $3.76-5.36$ & 4.67 \\
\hline 4 & Trikaripur & $4.53-6.28$ & 5.54 & 19 & Kasargode & $4.97-5.02$ & 5.00 \\
\hline 5 & Kodombelur & $4.93-6.58$ & 5.82 & 20 & Chengala & $4.45-5.48$ & 5.04 \\
\hline 6 & Kinanur & $4.75-5.33$ & 5.17 & 21 & Manjeswar & 5.94-7.08 & 6.63 \\
\hline 7 & Kanhangad & $4.57-7.44$ & 6.13 & 22 & Vorkadi & $5.57-6.84$ & 6.37 \\
\hline 8 & Kayyur Chemeni & $4.59-5.75$ & 5.21 & 23 & Mangalpady & $4.71-6.31$ & 5.56 \\
\hline 9 & Chemnad & $5.16-5.31$ & 5.26 & 24 & Panathady & 6.07-6.41 & 6.19 \\
\hline 10 & Uduma & $5.43-5.81$ & 5.69 & 25 & Kallar & $5.93-6.30$ & 6.03 \\
\hline 11 & Pallikara & $4.63-5.64$ & 5.25 & 26 & Karadukka & $4.93-5.76$ & 5.41 \\
\hline 12 & Pullur Periya & $4.28-5.75$ & 5.28 & 27 & Muliyar & $5.01-5.75$ & 5.31 \\
\hline 13 & Puthige & $4.91-5.45$ & 5.24 & 28 & Paivaligai & $5.50-6.85$ & 6.33 \\
\hline 14 & Kuttikol & $4.88-5.55$ & 5.30 & 29 & Belur & $5.18-6.55$ & 5.72 \\
\hline 15 & Meencha & $5.76-6.17$ & 6.01 & 30 & Kumbadaje & $5.43-6.95$ & 5.66 \\
\hline
\end{tabular}

\section{Available micronutrients}

Table 2: Available micronutrient status in rice soils of Kasaragode.

\begin{tabular}{|c|c|c|c|c|c|c|c|c|c|c|c|}
\hline \multirow{2}{*}{ S. No. } & \multirow{2}{*}{ Location } & \multicolumn{2}{|c|}{ Av. Cu (mg kg $\left.{ }^{-1}\right)$} & \multicolumn{2}{|c|}{ Av. Zn $\left(\mathrm{mg} \mathrm{kg}^{-1}\right)$} & \multicolumn{2}{|c|}{ Av. B $\left(\mathrm{mg} \mathrm{kg}^{-1}\right)$} & \multicolumn{2}{|c|}{ Av. Mn (mg kg-1) } & \multicolumn{2}{|c|}{ Av. Fe (mg kg-1) } \\
\hline & & & Mean & Range & & Range & Mean & & Mean & & Mean \\
\hline 1 & Pilicode & $0.18-1.94$ & & $3.18-18.53$ & & $0.08-0.624$ & & $13.10-25.53$ & & $12.21-269.5$ & 201.7 \\
\hline 2 & Cheruv & & & & & & & & & & 275.4 \\
\hline 3 & & & & & & & & & 14.23 & & 176.9 \\
\hline 4 & & & & & & & & & 26.04 & & 87.1 \\
\hline 5 & & & & & 6.46 & & 0.56 & & 18.37 & $83.62-234.5$ & 149.6 \\
\hline 6 & & & & & 14.34 & & 0.64 & & 34.21 & & 152.4 \\
\hline 7 & & & 12.26 & & 12.06 & & & & 34.06 & & 174.2 \\
\hline 8 & Kayyu & & 10.61 & & 9.64 & & & & 31.32 & & 173.4 \\
\hline 9 & & & 10.44 & & 15.09 & & & & 26.39 & & 227.5 \\
\hline 10 & & & & & & & & & 31.47 & & 169.8 \\
\hline 11 & & & & & & & & & 38.06 & & 173.4 \\
\hline 12 & & & & & & & & & 19.26 & & 104.6 \\
\hline 13 & & & 18.46 & 9.79 & 14.18 & & 0.2 & & 22.38 & & 174.1 \\
\hline 14 & & & 7.91 & & 32.31 & & & & 31.49 & & 203.8 \\
\hline 15 & & & 10.63 & & 1.24 & & 0.47 & & 29.71 & & 74.3 \\
\hline 16 & & & 11.49 & & & & & & 18.98 & & 176.2 \\
\hline 17 & & & 9.66 & 31.12 & 24.16 & & & & 24.63 & & 131.8 \\
\hline 18 & & & & & & & & & 28.46 & & 243.6 \\
\hline 19 & & & 10.07 & & & & & & 29.03 & $58.52-74.12$ & 69.3 \\
\hline 20 & & & & & & & & & 34.21 & & 102.4 \\
\hline 21 & & & & & & & & & 28.97 & & 132.7 \\
\hline 22 & & & 17.32 & & & & & & 46.23 & 09.5 & 142.8 \\
\hline 23 & & & & & & & & & 31.04 & & \\
\hline 24 & & & & & & & & & 29.67 & 0.6 & 149.6 \\
\hline 25 & & & & & & & & & 43.32 & & 123.8 \\
\hline 26 & & & & & 23.06 & & & & 38.91 & & 51.2 \\
\hline 27 & & & & & & & & & 29.41 & & 102.7 \\
\hline 28 & & & & & & & & & 19.13 & & 11.3 \\
\hline 29 & & & & & 11.04 & & & & 24.61 & & 102.8 \\
\hline 30 & Kumbadaje & $3.98-6.27$ & 4.82 & $5.87-11.38$ & 7.13 & $0.064-0.289$ & 0.16 & $15.87-27.23$ & 18.97 & $27.36-80.66$ & 49.3 \\
\hline
\end{tabular}

\section{Available zinc}

The available $\mathrm{Zn}$ content in soil varied from $0.66-38.15 \mathrm{mg}$ $\mathrm{kg}^{-1}$. The lowest value was observed from Trikaripur and the highest from Kuttikol. The available $\mathrm{Zn}$ content is adequate in $98 \%$ and deficient in $2 \%$ samples while considering the critical limits for $\mathrm{Zn}<1 \mathrm{mg} \mathrm{kg}^{-1}$ is deficient, $>1 \mathrm{mg} \mathrm{kg}^{-1}$ is adequate and $>40 \mathrm{mg} \mathrm{kg}^{-1}$ is high (fig. 1). The solubility of native as well as applied zinc is highly $\mathrm{pH}$ dependent and the acid $\mathrm{pH}$ that occurs in the soil is expected to enhance the solubility of $\mathrm{Zn}$ which might have increased the available $\mathrm{Zn}$ in the soil. This is in agreement with the findings of Sharma et al. (2003) ${ }^{[3]}$. 


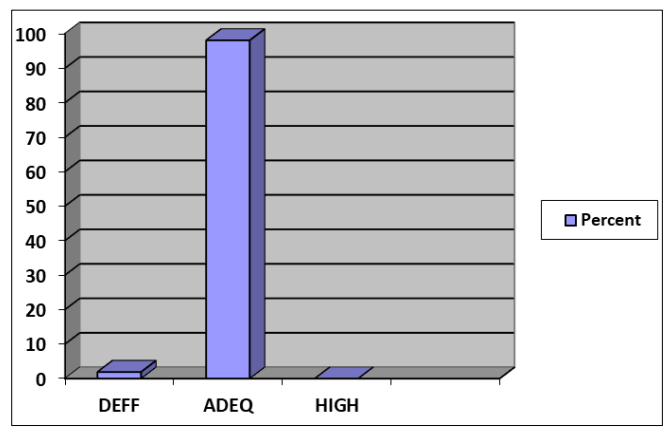

Fig 1: Frequency of Zinc classes $(n=3500)$

\section{Available copper}

The available copper content in soil varied from 0.18 to 36.5 $\mathrm{mg} \mathrm{kg}^{-1}$. The lowest value was observed from Pilicode and the highest from Karadukka. On the basis of the critical limits suggested for soil available copper $<1 \mathrm{mg} \mathrm{kg}^{-1}$ for deficient, $>1 \mathrm{mg} \mathrm{kg}^{-1}$ for adequate and $>20 \mathrm{mg} \mathrm{kg}^{-1}$ for high, $2.9 \%$ samples are deficient, $89.8 \%$ adequate and $7.3 \%$ high in available $\mathrm{Cu}$ (fig.2). The amount of copper released in soil solution depends on soil $\mathrm{pH}$, with the increase in soil $\mathrm{pH}$ the amount of available $\mathrm{Cu}$ in soil decreases. The solubility and mobility of copper in soil also decreases with increased $\mathrm{pH}$ and a significant negative relationship exists between $\mathrm{pH}$ and amount of available $\mathrm{Cu}$. The low $\mathrm{pH}$ in these soils might have increased the solubility and availability of $\mathrm{Cu}$ in soil as reported by Das (2007) ${ }^{[1]}$.

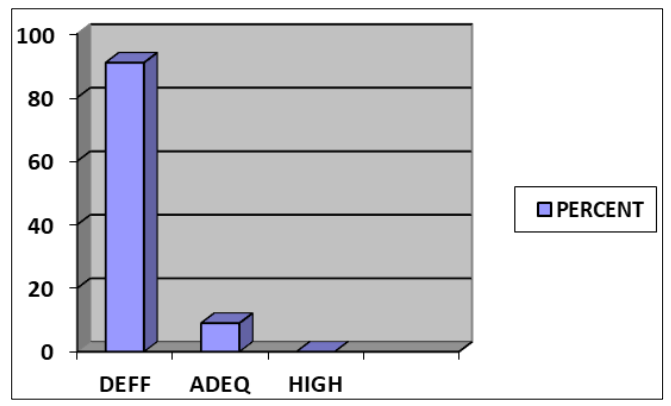

Fig 2: Frequency of Copper classes $(n=3500)$

\section{Available Boron}

The hot water-soluble boron content in soil varied from 0.027 to $0.984 \mathrm{mg} \mathrm{kg}^{-1}$. The lowest value was observed from Cheruvathur and the highest from Kinanur. As per the critical values suggested for boron viz., $<0.5 \mathrm{mg} \mathrm{kg}^{-1}$ for deficient, $0.5-2.0 \mathrm{mg} \mathrm{kg}^{-1}$ for adequate and $>2.0 \mathrm{mg} \mathrm{kg}^{-1}$ for high, $91 \%$ of the soils were found to be deficient and $9 \%$ adequate in soil available boron (fig. 3). The highest rate of deficiency for boron in the soils is attributed to the strong acidity prevails in that soil. The soils being lateritic, high amount of available $\mathrm{Fe}$ and $\mathrm{Al}$ form complex with $\mathrm{B}$ and might have reduced its availability in soil. The deficiency is also more pronounced in high rainfall areas where $\mathrm{B}$ is leached form the soil as reported by Das (2007) ${ }^{[1]}$.

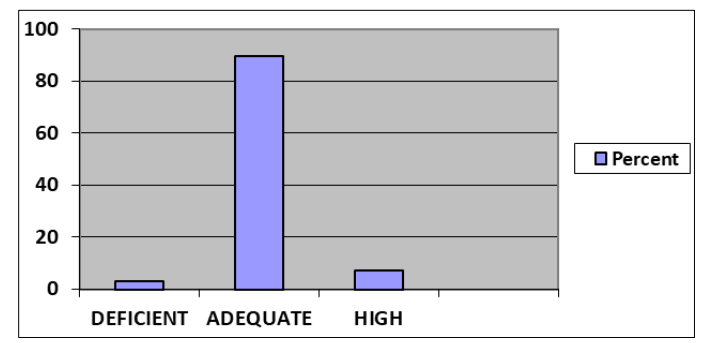

Fig 3: Frequency of Boron classes $(\mathrm{n}=3500)$

\section{Available Manganese}

The available manganese content in soil ranged from $12.21-$ $54.80 \mathrm{mg} \mathrm{kg}^{-1}$ and is in the excess range (critical limit is 1.0 $\mathrm{mg} \mathrm{kg}^{-1}$ ). The lowest value was observed from Padana and the highest from Kayyur Chemeni. This is attributed to the dominance of parent material in manganese bearing mineral and also the lateritic soils with low $\mathrm{pH}$ contains large concentration of $\mathrm{Mn}^{2+}$ in solution because of the increased solubility of Mn bearing minerals which is similar with the results reported by Wani et al. (2010) ${ }^{[6]}$.

\section{Available Iron}

All the soils under study fall under excess (> $5 \mathrm{mg} \mathrm{kg}^{-1}$ ) category for available iron status. The content of $0.1 \mathrm{~N} \mathrm{HCl}$ extractable Fe in soil varied from $6.25-414.9 \mathrm{mg} \mathrm{kg}^{-1}$. The lowest value was observed from Mangalpady and the highest from Nileswar. Toxic concentration of iron was also observed in some soils of the study area which is given in table 2.The concentration of $\mathrm{Fe}^{2+}$ increases due to the reason that the midland rice fields of study area constitute the drainage basins of hills and hillocks, which accumulates all the leachates washed down from hills and the soils being lateritic which are high in iron content, the extent of reduced forms of iron accumulating is also high as reported by Jena (2013) ${ }^{[2]}$ in acid soils of Odisha.

\section{Conclusion}

From the study it is concluded that the rice soils of Kasaragode are strongly acidic to neutral in reaction, deficient in boron and adequate in copper, zinc, iron and manganese. Toxic concentrations of iron was also present in some soils. The results suggest the need of boron fertilization in these soils to enhance rice production and also lime application to reduce soil acidity and iron toxicity problems.

\section{Reference}

1. Das DK. Micronutrients: their behavior in soils and plants. Kalyani publishers, New Delhi, 2007, 10-55.

2. Jena D. Acid soils of Odisha. In: Acid soils their chemistry and management. (A.K. Sarkar, Ed.), 2013, 197.

3. Sharma RP, Megh Singh, Sharma JP. Correlation studies on micronutrients vis-a-vis soil properties in some soils of Nagpur district in semi-arid region of Rajasthan. J. Indian soc. soil sci., 2003; 51:522-527.

4. Somasudaram J, Sigh RK, Parandiyal AK, Prasad SN. Micronutrient status of soils under land use system in Chambal ravines. J. Indian soc. Soil Sci., 2009; 57:307312.

5. Vejkatesh MS, Majumda B, Kumar K, Patiram. Status of micronutrient cations under various land use system of Meghalaya. J. Indian soc. soil Sci., 2003; 51:60-64.

6. Wani MA, Zahid Mushtaq, Shaistra Nazir. Mapping of micronutrients of the submerged rice soils of Kashmir. Res. J. Agrl. Sci., 2010; 1(4):458-462. 